\title{
Regional Cerebral Glucose Utilization in the Immature Rat: Effect of Hypoxia-Ischemia
}

\author{
ROBERT C. VANNUCCI, MELANIE A. CHRISTENSEN, AND DAGMAR T. STEIN \\ Department of Pediatrics (Pediatric Neurology), The Milton S. Hershey Medical Center, The Pennsylvania State \\ University, Hershey, Pennsylvania 17033
}

\begin{abstract}
The 2-deoxy- $\left[{ }^{14} \mathrm{C}\right]$-glucose (2-DG) method of Sokoloff was used to assess regional cerebral glucose utilization (CGU) in the immature rat. The 7-d postnatal rats received $2.5 \mu \mathrm{Ci} 2-\mathrm{DG}$ subcutaneously, after which blood was collected for measurement of plasma glucose and 2DG activity at intervals up to $90 \mathrm{~min}$. The brains of the 90-min rat pups either were frozen for analysis of glucose concentration and chromatographic separation of 2-DG and 2-DG-6-phosphate or for $\left[{ }^{14} \mathrm{C}\right]$-autoradiography. A lumped constant of 0.55 was calculated from plasma and brain glucose levels of 6.4 and $1.62 \mathrm{mmol} / \mathrm{L} \cdot \mathrm{kg}$, respectively. Of the $\left[{ }^{14} \mathrm{C}\right]$ activity in brain, $75.6 \%$ was in the 2 DG-6-phosphate fraction; this percent was substituted for $\mathrm{K} 1 *$, $\mathrm{K} 2 *$, and $\mathrm{K} 3 *$ in the Sokoloff equation. Cerebral hemispheric CGU $(n=6)$ averaged $11.4 \pm 1.5 \mu \mathrm{mol} / 100$ $\mathrm{g} / \mathrm{min}, \mathbf{1} / 10$ the value of adult rat brain. Rates in 16 brain structures $(n=10)$ ranged from 7.8 (frontal white matter) to 16.9 (cerebellum) $\mu \mathrm{mol} / 100 \mathrm{~g} / \mathrm{min}$. During hypoxiaischemia (unilateral common carotid artery ligation combined with exposure to $8 \%$ oxygen), the lumped constant increased to 1.04 , and $99 \%$ of $2-D G$ was converted to 2 DG-6-phosphate. Increases in CGU occurred in all eight structures of the cerebral hemisphere ipsilateral to the carotid artery occlusion $(n=9)$, ranging from $287 \%$ (frontal white matter) to $445 \%$ (striatum) of control values ( $p$ $<0.05)$. Relatively comparable elevations in CGU (234$435 \%$ of control) occurred in the contralateral cerebral hemisphere, which were not significantly different from those of the ipsilateral hemisphere. The relatively proportionate increases in regional CGU of the two cerebral hemispheres, only one of which sustains tissue injury, suggest interhemispheric differences in the extent to which glucose is metabolized via anaerobic glycolysis to maintain cellular energy production. The investigation demonstrates the feasibility of measuring regional CGU in the small laboratory animal, which is applicable to a variety of physiologic and pathologic situations. (Pediatr Res 26: 208-214, 1989)
\end{abstract}

\section{Abbreviations}

CGU, cerebral glucose utilization

rCGU, regional CGU

2-DG, 2-deoxyglucose

2-DG-6-P, 2-deoxyglucose-6-phosphate

s.c., subcutaneous

LC, lumped constant

$\sim \mathbf{P}$, high-energy phosphate bond

Received December 15, 1988; accepted May 17, 1989

Correspondence Robert C. Vannucci, M.D., Department of Pediatrics, The Milton S. Hershey Medical Center, The Pennsylvania State University, P.O. Box 850 , Hershey, PA 17033.

Supported by Grant HD 19913 from the National Institute of Child Health and Human Development.
The 2-DG technique, as originally developed by Sokoloff et al. (1), has become an established procedure to measure rCGU in adult animals. The method has been used in numerous species under a variety of physiologic and pathologic situations (2). Furthermore, the method provides the theoretical and practical basis for the measurement of rCGU in humans, including infants and children, using positron emission tomography $(3,4)$. Although rCGU has been determined in large perinatal animals (5-7), a systematic investigation of its applicability to the small laboratory animal has yet to be accomplished. We here describe a feasibility study to measure rCGU, using 2-DG, in the immature rat; and we have used the technique to ascertain the nature and extent of alterations in regional glucose metabolism in a model of perinatal hypoxic-ischemic brain damage.

\section{MATERIALS AND METHODS}

Dated pregnant Wistar rats were purchased from a commercial breeder (Charles River, Wilmington, MA) and housed in individual cages. Offspring, delivered vaginally, were reared with their dams until time of experimentation at $7 \mathrm{~d}$ of postnatal age.

Measurement of $r C G U$. rCGU was measured with a modification of the original Sokoloff technique (1) using 2-DG as the radioisotope. A preliminary study was conducted to characterize the saturation/desaturation plasma curve for $2-D G$ in $7-d$ postnatal rats. A total of 21 rat pups from three litters of 10 or more animals received a s.c. injection of $2.5 \mu \mathrm{Ci}(0.2 \mathrm{~mL}) 2$-deoxy-[U$\left.{ }^{14} \mathrm{C}\right]$-glucose $(58.0 \mathrm{mCi} / \mathrm{mmol})$ (Amersham, Arlington Heights, IL), after which the animals were decapitated at varying intervals up to $180 \mathrm{~min}$. Arterialized blood (8) was collected from the severed neck vessels into heparinized capillary tubes that were centrifuged at $3000 \times g$ for 5 min to separate plasma from red cells. Ten $\mu \mathrm{L}$ of plasma then was solubilized in $1.0 \mathrm{~mL}$ of Soluene-350 (United Technologics Packard, Downer Grove, IL). After mixing overnight in a mechanical shaker at room temperature, the solution was combined with $9.0 \mathrm{~mL}$ of Dimilume-36 (United Technologics Packard). Samples then were counted on a Beckman LS-350 liquid scintillation spectrometer (Beckman Instruments, Inc., Fullerton, CA) with appropriate internal standards and blanks.

The results of the preliminary study are shown in Figure 1. Plasma 2-DG concentrations, represented in $\mathrm{dpm} / \mathrm{mL}$, peaked within $5 \mathrm{~min}$ of s.c. injection, remained stable for an additional $25 \mathrm{~min}$ and decreased thereafter to $10 \%$ of the peak value by $180 \mathrm{~min}$. The prolonged decay of the plasma curve compared to adult rats (1) presumably relates to the route of administration of the isotope (s.c. vs intravenous) and to slow clearance of the isotope from the bloodstream. Calculation of several areas under the curve from 0 to $180 \mathrm{~min}$ revealed that saturation/desaturation of plasma 2-DG was 70, 80, and 90\% complete at 45, 60, and $90 \mathrm{~min}$, respectively. Assuming that nonphosphorylated 2DG in brain follows closely that of plasma (see below), autoradiography would best be accomplished 90 min or longer postinjection of the isotope to minimize overestimation of rCGU owing 


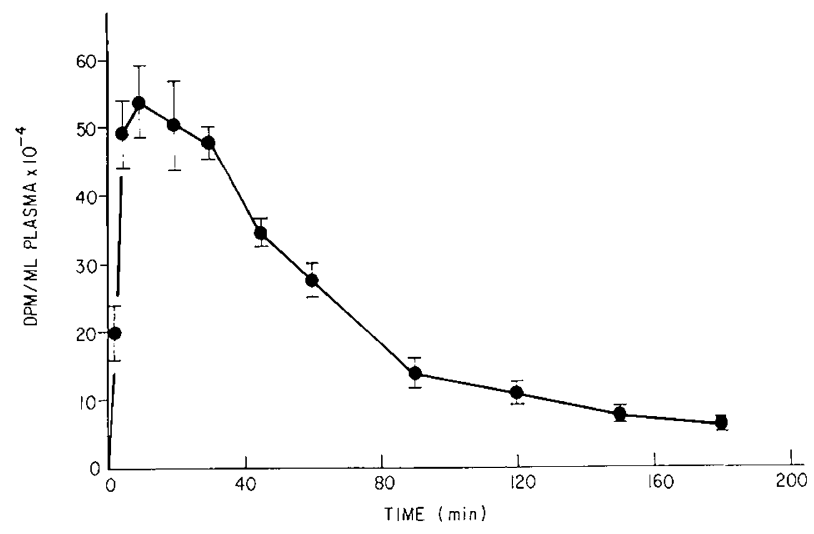

Fig. 1. Plasma saturation/desaturation curve of 2-deoxy- $\left[{ }^{14} \mathrm{C}\right]$-glucose in immature rats. The 7 -d postnatal rats received $2.5 \mu \mathrm{Ci} 2$-deoxy$\left[\mathrm{U}^{14} \mathrm{C}\right] \mathrm{glucose}$ after which blood was collected for plasma radioactivity at intervals up to $180 \mathrm{~min}$. Symbols represent means of three to five animals; vertical lines denote $\pm 1 \mathrm{SE}$.

to the presence of substantial amounts of nonmetabolized 2-DG in the tissue $(1,2)$.

In further experiments, 7-d-old rats were injected s.c. with 2.5 $\mu \mathrm{Ci} 2$-deoxy-[ $\left.\mathrm{U}^{14} \mathrm{C}\right]$-glucose, after which two or more animals were decapitated at either $2,5,10,20,30,45,60,75$, or $90 \mathrm{~min}$. Blood was collected from the severed neck vessels and plasma separated from red cells by centrifugation (see above). A portion $(10 \mu \mathrm{L})$ of plasma was used to determine glucose concentration on a micro-glucose analyzer (Beckman Glucostat), whereas 10 $\mu \mathrm{L}$ of the remaining portion were prepared for scintillation counting as described above. Measurement of the glucose $(\mu \mathrm{mol} /$ $\mathrm{mL})$ and 2-DG (dpm/mL) contents in each plasma sample allowed calculation of the integrated 2-DG/glucose sp act (dpm/ $\mu \mathrm{mol}$ ) over $90 \mathrm{~min}$ (average of two or more samples at each interval). A total of three sets of two combined litters (20-24 animals) of comparable age and size were used for this experiment.

The heads of the rat pups killed at 90 min postinjection of 2DG were immediately frozen in liquid nitrogen to stop intermediary metabolism. Each brain then was removed from its skull in a cold box set at $-20^{\circ} \mathrm{C}$, and portions $(50-80 \mathrm{mg}$ ) of cerebral cortex and subcortical white matter from each cerebral hemisphere and of the brainstem were dissected, powdered under liquid nitrogen and weighed on a micro-analytical balance. Perchloric acid extracts of each major brain region then were prepared as previously described (9). The solutions were neutralized to $\mathrm{pH} 7.0$ with $2 \mathrm{M} \mathrm{KHCO}_{3}$, a portion $(0.5 \mathrm{~mL})$ of which was diluted in $9.5 \mathrm{~mL}$ of Dimilume-36 and counted in the scintillation spectrometer. An additional aliquot $(20 \mu \mathrm{L})$ of the extract was assayed for glucose content using an enzymatic, fluorometric technique (9). The remainder of the neutralized perchloric acid extract was passed over an ion-exchange column formate form (Biorad Econocolumn, Richmond, CA). Neutral compounds, including free (nonphosphorylated) 2-DG and glucose, were eluted with $3 \mathrm{~mL}$ water, a portion of which $(0.5 \mathrm{~mL})$ was diluted in $9.5 \mathrm{~mL}$ Dimilume-36 and counted. From the data, the percentage of total 2-DG in brain which was metabolized to 2-DG6-P was calculated (see "Results").

The brains of three additional rats killed at 90 min postinjection of 2-DG were removed fresh from their skulls and frozen in liquid freon $\left(-70^{\circ} \mathrm{C}\right)$. Coronal sections of brain were cut at 20 $\mu \mathrm{M}$ thickness in a cryostat (American Optical, Buffalo, NY) kept at $-12^{\circ} \mathrm{C}$. Sections were mounted on glass slides, dried and subjected to quantitative $\left[{ }^{14} \mathrm{C}\right]$-autoradiography along with $\left[{ }^{14} \mathrm{C}\right]$ -methymethacrylate standards. The standards previously had been calibrated against standards for $20 \mu \mathrm{M}$ dried brain tissue sections by the manufacturer (Amersham). Comparison of the optical densities of $0.5-\mathrm{mm}$ portions of the autoradiograms cor- responding to specific regions of brain with those of the carbon14 standards yielded concentrations of $2-D G$ in $\mathrm{dpm} / \mathrm{g}$ of tissue.

Several rate constants are incorporated into the operational equation of Sokoloff et al. (1) to measure rCGU. These rate constants include: $\mathrm{K} 1 *=2-\mathrm{DG}$ transport into brain; $\mathrm{K} 2 *=2$ $\mathrm{DG}$ efflux from brain into blood; and $\mathrm{K} 3^{*}=$ the tissue phosphorylation of 2-DG to 2-DG-6-P. Use of these rate constants, which differ from those of glucose, is required to estimate the amount of nonmetabolized 2-DG present in brain at the time that the animals were killed. Without use of the constants, calculated rCGU would overestimate the true value, because isotopic counting of brain tissue specimens (or autoradiography) includes both 2-DG and 2-DG-6-P radioactivities. Sokoloff $e t$ al. (1) emphasized that any error in calculating CGU of adult rat brain using the rate constants is minimized by the prolonged circulation time (45 min) of 2-DG before the animals were killed. During this time, the terms of the 2-DG equation that contain the rate constants should approach zero. However, recent data indicate that the 2-DG rate constants of immature (specifically newborn) rats differ from those of adult (10). Furthermore, immature and adult rats differ both in their basal concentrations of plasma and brain glucose (higher in rat pups) and in the rates of cerebral metabolism (lower in rat pups) $(1,9,11,12)$. These age-related differences precluded the use of published 2-DG rate constants in our experiments on 7 -d-old rats.

To determine $\mathrm{K} 1^{*}, \mathrm{~K} 2^{*}$, and $\mathrm{K} 3^{*}$ in immature rat brain would have required a large number of animals. Therefore, we used the data obtained from the chromatographic experiments described above to ascertain the ratio of 2-DG-6-P to that of total $\left[{ }^{14} \mathrm{C}\right]$ activity in brain. This ratio then was substituted for those components of the original Sokoloff equation containing the rate constants (see below).

$\mathrm{K} 4 *$ is a constant which describes the rate of dephosphorylation of 2-DG-6-P to 2-DG by glucose-6-phosphatase. Sokoloff et al. (1) proposed that the dephosphorylation of 2-DG-6-P is negligible; therefore, $\mathrm{K} 4 *$ can be ignored (13). However, other investigators have provided evidence to suggest that substantial conversion of 2-DG-6-P to 2-DG occurs and that $\mathrm{K} 4^{*}$ should not be ignored $(14,15)$. Based on an appraisal of the available data, Gjedde (16) has concluded that for adult rat brain "there is no compelling reason to include a term for dephosphorylation in solutions- of the Sokoloff equation-that do not extend beyond 45 minutes." We would extend this conclusion to 90 min for immature rat brain, in which the activities of glycolytic enzymes, and presumably glucose- 6 -phosphatase, are $50 \%$ or less of the enzymatic activities of adult rat brain $(17,18)$.

The LC of the Sokoloff equation is a value that defines a composite of six individual constants representing: 1$)$ the ratio of the distribution volumes $(\lambda)$ for $2-D G$ and glucose in brain, 2 ) the relative activity of brain glucose-6-phosphatase $(\phi)$, and 3) the apparent Michaelis-Menton constants $\left(\mathrm{Km}\right.$ and $\left.\mathrm{Km}^{*}\right)$ and maximal velocities ( $\mathrm{Vm}$ and $\mathrm{Vm}^{*}$ ) of brain hexokinase for glucose and $2-\mathrm{DG}$, respectively $(1,2)$. The LC already has been determined to be 0.46 for adult rat brain (1) and 0.61 for newborn rat brain (10). Rather than measure the LC directly in 7-d-old rats, we elected to use a ng for adult rat brain published by Pardridge et al. (19) that allows calculation of individual LC values for each animal as determined by the concentrations of glucose in brain relative to that of plasma.

As mentioned previously, we used a modification of the original Sokoloff equation to measure rCGU in immature rat brain by substituting the measured values of the percent $2-D G$ metabolized for the rate constants (20). Thus,

$$
\begin{aligned}
& \mathrm{CGU}(\mu \mathrm{mol} / 100 \mathrm{~g} / \mathrm{min})= \\
& \qquad \frac{\mathrm{Ci}(\mathrm{T}) \times\left(2-\left[{ }^{14} \mathrm{C}\right]-\mathrm{DG}-6-\mathrm{P} / \mathrm{Total}\left[{ }^{14} \mathrm{C}\right]\right)}{(\mathrm{LC})\left[\int_{0}^{T} \frac{\mathrm{Cp}}{\mathrm{Cp}}\right] \mathrm{dt}} \times 100
\end{aligned}
$$

where: $\mathrm{Ci}^{*}(\mathrm{~T})=$ the concentration of the tracer in brain at time 
(T) $(\mathrm{dpm} / \mathrm{g}) ; \mathrm{Cp}^{*}=$ the concentration of the tracer in plasma $(\mathrm{dpm} / \mathrm{mL})$; and $\mathrm{Cp}=$ the concentration of glucose in plasma $(\mu \mathrm{mol} / \mathrm{mL})$

Induction of hypoxia-ischemia. Cerebral hypoxia-ischemia was induced in 7-d postnatal rats by a previously described technique (21). Specifically, individual rat pups were lightly anesthetized with halothane (4\% induction; $1.0-1.5 \%$ maintenance) during which the right common carotid artery was permanently ligated with 4-0 surgical silk. Upon recovery from anesthesia, the animals were returned to their dams for $4 \mathrm{~h}$, after which each animal received a s.c. injection of $2.5 \mu \mathrm{Ci} 2$-deoxy-[ $\left.\mathrm{U}^{14} \mathrm{C}\right]$-glucose. Then 5 min later, they were placed in $500-\mathrm{mL}$ air-tight jars partially submerged in a $37^{\circ} \mathrm{C}$ waterbath, through which was delivered a humidified gas mixture of $8 \%$ oxygen- $92 \%$ nitrogen via inlet and outlet portals. This insult is known to produce irreversible brain damage in the form of selective neuronal necrosis and/or infarction predominantly in the cerebral hemisphere ipsilateral to the arterial occlusion in $92 \%$ of the animals (21). The rat pups were exposed to hypoxia-ischemia for $2,5,10,20,30,45,60$, 75 , or $90 \mathrm{~min}$, after which they were rapidly removed from the jars and killed by decapitation. Plasma and brain specimens $(90$ min) were prepared for assay of glucose content, scintillation counting, and/or autoradiography as described above for the control 7-d-old rat pups. Thus, control (no ligation or hypoxia) and hypoxic-ischemic animals were obtained from entirely separate litters, owing to the necessity to characterize the plasma 2 DG saturation-desaturation curve for each experimental group.

Statistical analysis. Statistical analysis of the data included the paired and unpaired Student's $t$ tests and an analysis of variance.

\section{RESULTS}

Table 1 depicts data obtained from experiments whereupon the brains of six 7-d postnatal rats were quick frozen $90 \mathrm{~min}$ after a s.c. injection of 2-deoxy- $\left[{ }^{14} \mathrm{C}\right]$-glucose (2-DG). These brains were subjected to those chromatographic procedures necessary to ascertain the extent to which $2-D G$ in brain was phosphorylated to 2-DG-6-P. As can be seen from Table 1, under physiologic conditions (control animals), $75.6 \%$ of the metabolite retained by brain during isotopic circulation underwent metabolic conversion to 2-DG-6-P, $24.4 \%$ remaining as nonphosphorylated 2-DG. Incorporating this constant into the numerator of the Sokoloff equation (see "Materials and Methods") and using a lumped constant of $0.55-0.56$, CGU for both cerebral hemispheres of control 7-d-old rat brain were calculated.

Six rat pups from three separate litter pairs underwent $90 \mathrm{~min}$ of cerebral hypoxia-ischemia, during which their brains were analyzed for measurement, of cerebral hemispheric CGU. The animals were injected with 2-DG $5 \mathrm{~min}$ before the onset of systemic hypoxia. Unlike the control rats (see above), the 2-DG entering brain was essentially completely phosphorylated in both cerebral hemispheres (Table 1). The metabolic conversion of 2 DG to 2-DG-6-P occurred in association with 91 and $76 \%$ decreases in brain glucose in the cerebral hemispheres ipsilateral (right) and contralateral to the carotid artery occlusion, respectively. Lumped constants nearly doubled in both hemispheres, owing to disproportionate reductions in brain glucose relative to that of plasma. CGU increased by $150 \%$ in the hypoxic-ischemic (right) cerebral hemisphere and by $135 \%$ in the nonischemic but hypoxic (left) hemisphere $(p<0.001)$.

Autoradiographic analyses were conducted in 10 control rat brains (Fig. 2). No interhemispheric differences in CGU were noted among several structures; therefore, only those of the right cerebral hemisphere are shown in Table 2. Rates of glucose utilization varied by as much as $50 \%$ among the gray matter structures, ranging from 8.7 to $16.9 \mu \mathrm{mol} / 100 \mathrm{~g} / \mathrm{min}$ for the striatum and cerebellar hemispheres, respectively. Cerebral cortical and brainstem rates were similar, whereas subcortical white matter showed the lowest rates of glucose metabolism.

The brains of nine immature rats subjected to $90 \mathrm{~min}$ of hypoxia-ischemia were prepared for $\left[{ }^{14} \mathrm{C}\right]$-autoradiography (Figs. 2 and 3). Increases in CGU occurred in all of eight analyzed structures of the cerebral hemisphere ipsilateral to the carotid artery occlusion, ranging from $287 \%$ (frontal white) to $445 \%$ (striatum) of control values ( $p=0.01-<0.001)$. Regional CGU also increased in the contralateral cerebral hemisphere $(p=0.01-$ $<0.001)$ although not to the extent seen in respective structures of the ipsilateral hemisphere. However, the interhemispheric differences in CGU during hypoxia-ischemia were not statistically significant in any of the eight analyzed structures $(p>$ 0.05 ).

Alterations in CGU also occurred in several brainstem structures during hypoxia-ischemia (Figs. 2 and 3). Greater increases in $\mathrm{CGU}$ were seen in the ipsilateral hypothalamus, midbrain, and colliculi when compared to the contralateral side, although the side-to-side difference was significant only in the midbrain $(p<0.001)$. Progressively less and relatively symmetrical increases in CGU occurred in the pons, cerebellar hemisphere, and medulla oblongata.

\section{DISCUSSION}

The results of the present investigation demonstrate our feasibility to measure quantitatively regional cerebral glucose utilization in a small laboratory animal, specifically the immature rat. The regional heterogenecity presented in Table 2 previously has been demonstrated in perinatal animals of other species (dog, monkey, sheep), in which rates of glucose utilization are highest

Table 1. Biochemical variables used to calculate cerebral hemispheric glucose utilization in control and hypoxic-ischemic immature rats*

\begin{tabular}{|c|c|c|c|c|}
\hline \multirow[b]{2}{*}{ Variable } & \multicolumn{2}{|c|}{ Control } & \multicolumn{2}{|c|}{ Hypoxia-ischemia } \\
\hline & Right & Left & Right & Left \\
\hline Plasma glucose $(\mathrm{mmol} / \mathrm{L})$ & $6.64 \pm 0.04$ & $6.64 \pm 0.04$ & $2.89 \pm 0.39 \dagger$ & $2.89 \pm 0.39 \dagger$ \\
\hline Brain glucose $(\mathrm{mmol} / \mathrm{kg})$ & $1.62 \pm 0.07$ & $1.42 \pm 0.06$ & $0.15 \pm 0.04 \dagger$ & $0.34 \pm 0.09 \dagger$ \\
\hline \multicolumn{5}{|l|}{ Brain radioactivity } \\
\hline Total $\left[{ }^{14} \mathrm{C}\right]\left(\mathrm{dpm} \times 10^{4} / \mathrm{g}\right)$ & $28.7 \pm 1.0$ & $28.7 \pm 1.0$ & $35.2 \pm 5.8$ & $28.5 \pm 4.0$ \\
\hline $2-\left[{ }^{14} \mathrm{C}\right]-\mathrm{DG}\left(\mathrm{dpm} \times 10^{4} / \mathrm{g}\right)$ & $7.0 \pm 0.3$ & $7.0 \pm 0.3$ & $0.40 \pm 0.08 \dagger$ & $0.41 \pm 0.06 \dagger$ \\
\hline $2-\left[{ }^{14} \mathrm{C}\right]-\mathrm{DG}-6-\mathrm{P}\left(\mathrm{dpm} \times 10^{4} / \mathrm{g}\right)$ & $21.7 \pm 0.9$ & $21.7 \pm 0.9$ & $34.8 \pm 6.3 \ddagger$ & $28.1 \pm 4.0$ \\
\hline $2-\left[{ }^{14} \mathrm{C}\right]-\mathrm{DG}-6-\mathrm{P} /$ Total $\left[{ }^{14} \mathrm{C}\right](\%)$ & $75.6 \pm 1.0$ & $75.6 \pm 1.0$ & $98.9 \pm 0.1 \dagger$ & $98.6 \pm 0.1 \dagger$ \\
\hline Lumped constant & $0.55 \pm 0.05$ & $0.56 \pm 0.05$ & $1.04 \pm 0.08 \dagger$ & $0.85 \pm 0.05 \dagger$ \\
\hline $\mathrm{CGU}(\mu \mathrm{mol} / 100 \mathrm{~g} / \mathrm{min})$ & $11.6 \pm 1.5$ & $11.2 \pm 1.5$ & $29.1 \pm 2.8 \dagger$ & $26.3 \pm 3.0 \dagger$ \\
\hline
\end{tabular}

* Values represent means \pm SEM for each cerebral hemisphere in six immature rats of each group. The right cerebral hemisphere was ipsilateral to the common carotid artery ligation in the hypoxic-ischemic animals. The lumped constants were derived from a nomogram published by Pardridge et al. (19) that relates the plasma to the brain glucose concentration. Abbreviations: $2-\left[{ }^{14} \mathrm{C}\right]-\mathrm{DG}, 2$-deoxy-[ $\left[{ }^{14} \mathrm{C}\right]$-glucose; $2-\left[{ }^{14} \mathrm{C}\right]-\mathrm{DG}-6-\mathrm{P}$,
2-deoxy- $\left[{ }^{14} \mathrm{C}\right]$-glucose-6-phosphate.

$\dagger p<0.001, \ddagger p<0.05$ compared to the respective cerebral hemisphere in the control animals. 
A
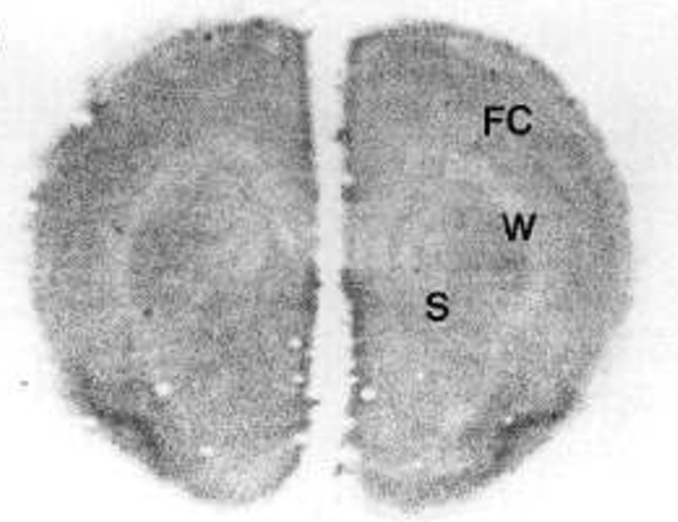

C

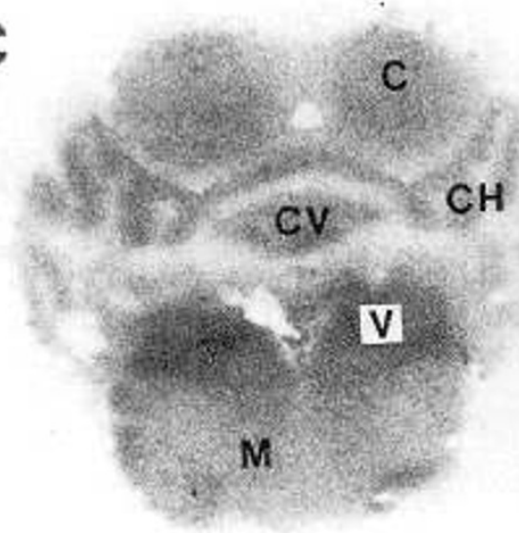

$\mathrm{E}$

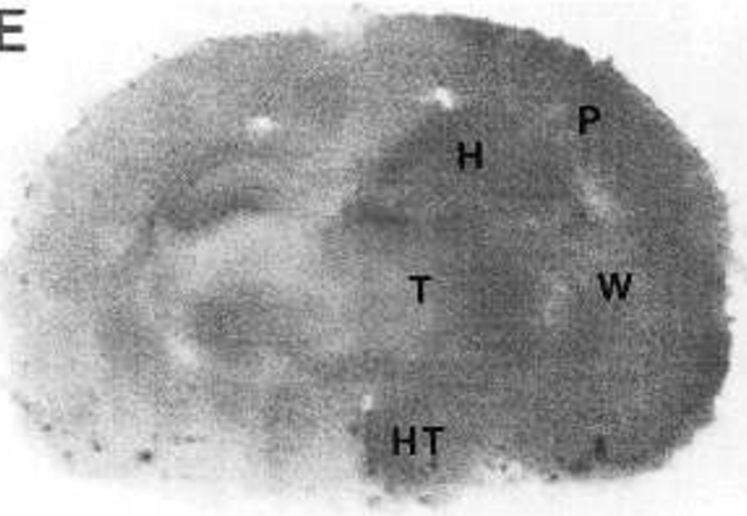

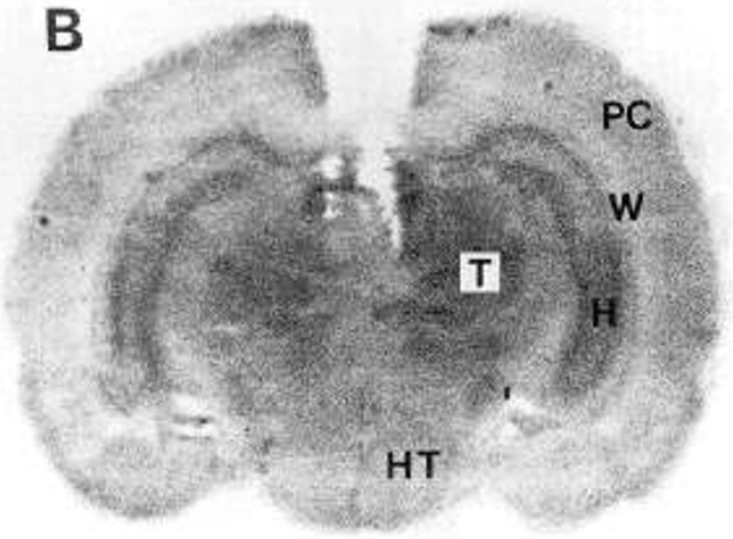
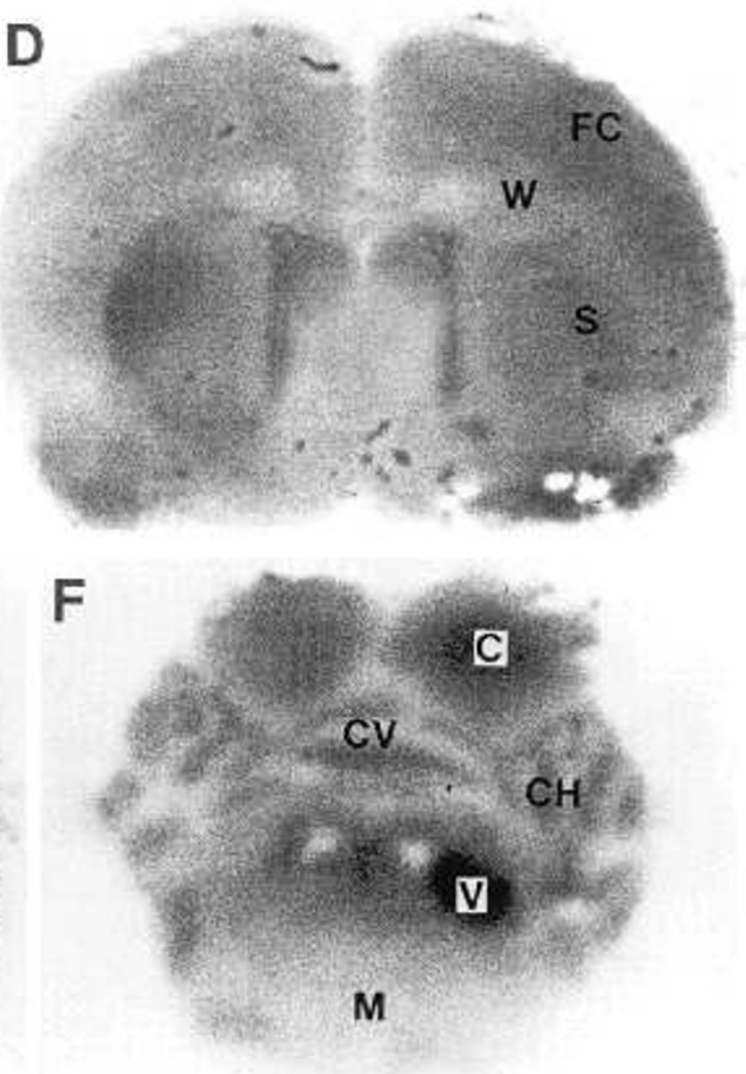

Fig. 2. Representative 2-deoxy- $\left[{ }^{14} \mathrm{C}\right]$-glucose autoradiograms of immature rat brain. Shown are coronal sections of autoradiograms in a control 7-d postnatal rat $(A-C)$ and in two rat pups $(D-F)$ subjected to unilateral (right) common carotid artery occlusion combined with hypoxia (8\% oxygen). Discernible structures include frontal cortex $(F C)$, subcortical white matter $(W)$, striatum $(S)$, parietal cortex $(P C)$, hippocampus $(H)$, thalamus $(T)$, hypothalamus $(H T)$, colliculus $(C)$, vestibular nucleus $(V)$, cerebellar vermis $(C V)$, cerebellar hemisphere $(C H)$, and medulla oblongota $(M)$.

in hindbrain structures (brainstem and cerebellum) and are lowest in white matter (5-7). The topographical variations in CGU presumably reflect underlying differences in local metabolic demands $(1,2)$; which, in turn, reflect the limited functional capabilities of the animal at the age under investigation (6). Thus, it is not surprising that $\mathrm{rCGU}$ is $70-92 \%$ lower than respective regional rates of adult rat brain (Table 2). The results also support an earlier finding from our laboratory in which the rate of cerebral energy use of 7-d postnatal rat brain was approximately $1 / 10$ the rate of adult rats (11).

The contribution of glucose consumption to the overall energy balance of the brain can be estimated if the rate of cerebral energy utilization is known. For 7-d postnatal rat brain, the energy use rate is $2.58 \mathrm{mmol} \sim \mathrm{P} / \mathrm{kg} / \mathrm{min}$ (11). For every mol of glucose aerobically consumed to carbon dioxide and water, 20 equivalents of $\sim \mathrm{P}$ are generated via the glycolytic pathway and oxidative phosphorylation, assuming and ADP/O ratio of 1.5 for immature rat brain $(22,23)$. A CGU rate of $11.4 \mu \mathrm{mol} / 100 \mathrm{~g} / \mathrm{min}$ (average of left and right cerebral hemispheres; Table 1) would generate $11.4 \times 20=228 \mu \mathrm{mol} \sim \mathrm{P} / 100 \mathrm{~g} / \mathrm{min}$ or $2.28 \mathrm{mmol} \sim \mathrm{P} / \mathrm{kg} / \mathrm{min}$. Therefore, under aerobic conditions, glucose oxidation would account for $2.28 / 2.58=88 \%$ of the energy requirement for $7-d-$ old rat brain.

However, the assumption that glucose in brain of the developing rat is degraded entirely by aerobic processes may not be correct. Under physiologic conditions in newborn animals of other species, glucose is consumed exclusively via the glycolytic pathway and the tricarboxylic (Krebs) cycle with little or no 


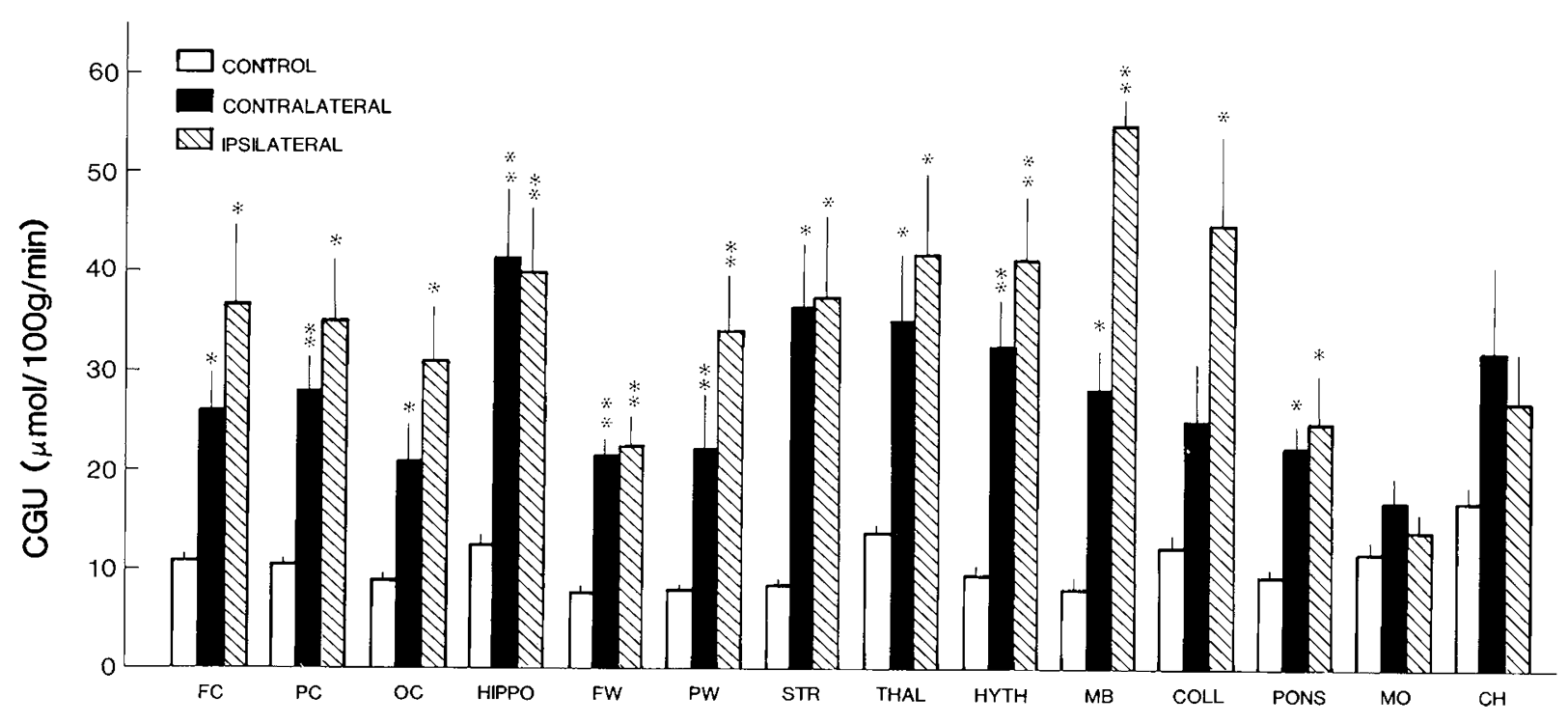

\section{STRUCTURE}

Fig. 3. rCGU during hypoxia-ischemia in immature rats. The 7-d postnatal rats were subjected to unilateral common carotid artery ligation combined with $90 \mathrm{~min}$ of systemic hypoxia ( $8 \%$ oxygen). Bars represent means of nine brains ipsilateral or contralateral to the common carotid artery ligation; vertical lines denote $\pm 1 \mathrm{SE}$. Control values are those depicted in Table $2 .{ }^{*} p<0.05 ;{ }^{* *} p<0.001$ compared to control. The Bonferroni correction for multiple comparisons and multiple regions requires $p<0.001$ to be highly statistically different from respective control values.

Table 2. $r C G U$ in Immature and adult rats

\begin{tabular}{|c|c|c|c|}
\hline \multirow[b]{2}{*}{ Structure } & \multicolumn{2}{|c|}{$\underset{\mathrm{min})}{\mathrm{CGU}(\mu \mathrm{mol} / 100 \mathrm{~g} /}$} & \multirow[b]{2}{*}{$\%$ Increase } \\
\hline & Immature & Adult & \\
\hline Frontal cortex & $11.1 \pm 0.6$ & $107 \pm 6$ & 861 \\
\hline Parietal cortex & $10.4 \pm 0.7$ & $112 \pm 5$ & 979 \\
\hline Occipital cortex & $8.9 \pm 0.7$ & $116 \pm 5$ & 1198 \\
\hline Hippocampus & $12.4 \pm 1.0$ & $79 \pm 3$ & 539 \\
\hline Frontal white & $7.8 \pm 0.5$ & & . \\
\hline Parietal white & $8.2 \pm 0.5$ & $34 \pm 1$ & 355 \\
\hline Occipital white & $6.5 \pm 0.7$ & & \\
\hline Striatum & $8.6 \pm 0.3$ & $110 \pm 4$ & 1167 \\
\hline Thalamus & $13.6 \pm 1.1$ & $113 \pm 5$ & 730 \\
\hline Hypothalamus & $9.6 \pm 0.8$ & $54 \pm 2$ & 464 \\
\hline Midbrain & $8.7 \pm 1.2$ & & \\
\hline Colliculus & $12.6 \pm 1.2$ & $95 \pm 5$ & 656 \\
\hline Pons & $9.4 \pm 1.1$ & $62 \pm 3$ & 562 \\
\hline Medulla oblongota & $11.7 \pm 1.0$ & & \\
\hline Cerebellar vermis & $15.6 \pm 1.9$ & & \\
\hline Cerebellar hemisphere & $16.9 \pm 1.3$ & $57 \pm 2$ & 236 \\
\hline
\end{tabular}

* Values represent means \pm SEM for 10 animals in each age group. Data for adult rats from Sokoloff et al. (1) where hippocampus $=$ Ammon's horn; white matter $=$ genu of corpus callosum; striatum $=$ caudate-putamen; thalamus = average of lateral and ventral nuclei; colliculus $=$ superior colliculus; cerebellar hemisphere $=$ cerebellar cortex.

production of lactic acid (24-26). Such is not the case for the immature rat, which during suckling actively generates ketone bodies (acetoacetate and $\beta$-hydroxybutyrate); the substrates can be transported into and consumed by brain (27-29). During postnatal development, the cerebral utilization of ketone bodies may actually exceed that of glucose; glucose, in turn, is converted in part to lactic acid which is lost from the brain $(27,29)$. Indeed, the data of Hawkins et al. (27), derived from cerebral arteriovenous difference measurements in 16- to 20-d-old rats, suggest that up to $21 \%$ of glucose is anaerobically degraded to lactate. If such is also the case for the 7-d-old rat, then the contribution of glucose to overall metabolism would equate to:

$$
[(11.4 \times 0.21 \times 2)+(11.4 \times 0.79 \times 20) / 100] / 2.58=71 \%
$$

of cerebral energy requirements (see above). It follows that to quantify regional differences in cerebral energy demands in the developing rat requires a knowledge of the rates of utilization of all substrates available to brain for metabolism. Unfortunately, the regional measurement of metabolic rates of substrates other than glucose is not yet available.

An investigation by Nehlig et al. (30) recently has been published that describes the developmental changes in rCGU, measured with 2-DG, of the rat from 10 postnatal d through adulthood. Rates of glucose utilization in 10-d-old rat pups were on the order of $80-120 \%$ higher than those presented here, although the regional differences were similar. Technical considerations, rather than maturational differences, most likely account for the major discrepancies in the rates of glucose utilization in the two investigations. In the study of Nehlig et al. (30), the lumped constant and rate constants used to calculate rCGU were those derived from adult rat brain (1), and the circulation time of 2deoxy- $\left[{ }^{14} \mathrm{C}\right]$-glucose was limited to $45 \mathrm{~min}$. As discussed in "Materials and Methods" and presented in "Results," the use of such constants are likely to overestimate substantially the true rates of glucose utilization in immature rat brain. Recalculation of frontal cortex CGU from the Nehlig et al. (30) study (20 $\mu \mathrm{mol} / 100 \mathrm{~g} / \mathrm{min}$ ) using our own constants provides a glucose utilization rate of $13.6 \mu \mathrm{mol} / 100 \mathrm{~g} / \mathrm{min}$, only $22 \%$ higher than the value found in 7-d-old rat brain (Table 2). A comparison of the data from the two studies emphasizes the inherent risk of extrapolating rate constants for the measurement of rCGU from adult to immature animals (31).

The potential difficulty of equating rCGU to local metabolic demands of the brain in the immature rat under physiologic conditions (see above) is circumvented in large part during hypoxia-ischemia, because all organic substrates other than glucose require oxygen for their metabolic degradation. Thus, the alterations in rCGU presented here can be assumed to reflect accurately regional differences in energy requirements and, 
hence, their respective vulnerabilities to hypoxic-ischemic injury. In this regard, the neuropathologic changes that characterize the immature rat subjected to cerebral hypoxia-ischemia is focused on the posterior cerebral cortex and subcortical white matter, hippocampus, striatum, and thalamus of the cerebral hemisphere ipsilateral to the carotid artery occlusion in decreasing order of incidence and severity (21). All of these structures exhibited substantial elevations in CGU during hypoxia-ischemia, although an inconsistent correspondence existed between the percent increases in CGU and the extent of brain damage (Table 3).

Although the alterations in CGU among several gray matter regions of the ipsilateral cerebral hemisphere correlated to some degree with the distribution and extent of ischemic tissue necrosis (Table 3), no such correspondence existed within individual brain structures. Specifically, the increases in CGU always appeared homogeneous within each brain structure (Fig. 3), whereas ischemic neuronal destruction follows distinctive patterns (21). In cerebral cortex, tissue injury shows either a laminar emphasis (layers 3 and $5+6$ ) or a contrasting pattern of alternating columns of normal and damaged neurons oriented at right angles to the pial surface. In hippocampus, ischemic damage is frequent in Sommer sectors $h 1$ and h3-5, with relative preservation of $h 2$. In the striatum, damage is maximal medially towards the ependyma of the lateral ventricle; in the thalamus, damage is always focal and usually limited to the lateral half. In other studies, we have shown columnar alterations in NADH fluorescence (as a reflection of the cellular oxidation-reduction state) and in the accumulation of radiolabelled $\mathrm{Ca}^{++}$in the same location of cerebral cortex and hippocampus as histologically verified tissue damage $(12,32)$. As with alterations in regional cerebral blood flow (33), pertubations in rCGU per se do not appear to predict the heterogeneous pattern of damage seen within individual structures of the brain. Further research is required to clarify the relationship between alterations in CGU and those of cellular acid-base balance and calcium ion homeostasis.

The observed increases in rCGU of the cerebral hemisphere ipsilateral to the carotid artery occlusion were not unexpected in light of previous findings that this hemisphere is rendered ischemic during the course of systemic hypoxia with $8 \%$ oxygen (33). Cerebral blood flow, measured with iodo- $\left[{ }^{14} \mathrm{C}\right]$-antipyrine, ranges from $15 \%$ (subcortical white matter) and $41 \%$ (thalamus) of control, whereas blood flows to the contralateral cerebral hemisphere are unchanged from prehypoxic values. During hypoxia-ischemia, both oxygen and substrate (glucose) delivery, including $2-D G$, to the ipsilateral cerebral hemisphere are curtailed. Thus, the elevations in rCGU reflect enhanced uptake into and utilization by brain, the latter most certainly via anaerobic glycolysis (12). Furthermore, glucose uptake does not keep pace with the accelerated glycolytic flux, resulting in near total depletion of endogenous glucose stores (Table 1). This finding is in keeping with the limited capacity of carrier-mediated glucose transport across the immature blood-brain barrier (34)

The question remains as to why the elevations in rCGU of the ipsilateral cerebral hemisphere were minimally greater than those

Table 3. Relationship between extent of brain damage and changes in cerebral glucose utilization (CGU) during hypoxiaischemia in immature rats*

\begin{tabular}{lcc}
\multicolumn{1}{c}{ Structure } & Brain damage (\%) & CGU (\% of control) \\
\hline Cerebral cortex & $92 / 56$ & 342 \\
Subcortical white matter & $92 /-$ & 413 \\
Hippocampus & $88 / 48$ & 322 \\
Striatum & $84 / 16$ & 445 \\
Thalamus & $68 / 24$ & 304 \\
\hline
\end{tabular}

* Data regarding extent of brain damage (\% damage/\% infarction) in 25 immature rats subjected to hypoxia-ischemia derived from Rice $e t$ al. (21). CGU as \% of control tabulated from the changes depicted in Figure 3. Cerebral cortex = average of pareital and occipital; subcortical white matter $=$ pareital. of the hypoxic but nonischemic contralateral hemisphere. Limited substrate (glucose and 2-DG) delivery to the hypoxic-ischemic hemisphere cannot account for the interhemispheric similarities in the rates of metabolism, because total 2-DG activity was actually $24 \%$ higher in the ischemic hemisphere (Table 1). A far more plausible explanation relates to a difference in the extent of anaerobic glycolysis of the two hemispheres. It is likely that in the ischemic hemisphere, most if not all of the available glucose was consumed anaerobically with little or no degradation via oxidative metabolism. Given the inefficiency of glycolysis to generate ATP, the high-energy phosphate compounds (ATP, ADP, phosphocreatine) would have been rapidly depleted, as has been shown to occur in this animal model (12). In contrast, glucose in the contralateral cerebral hemisphere was consumed to at least some extent by oxidative processes, thereby promoting optimal preservation of high-energy reserves (12). Unfortunately, lactic acid concentrations in brain during hypoxia-ischemia do not provide information regarding the extent of anaerobic glycolysis in the two hemispheres, because lactate in brain of the immature rat remains in close equilibrium with that of blood $(12,35)$. Hence, like rCGU, minimal interhemispheric differences in lactate levels exist (12).

In summary, the present investigation demonstrates the feasibility of measuring rCGU reliably and accurately in the small laboratory animal, specifically the immature rat. The method can be applied to a variety of situations to ascertain the role of glucose metabolism in influencing or controlling the functional homeostasis of the developing brain under physiologic and pathologic conditions. Such information should expand our knowledge regarding mechanisms of brain maturation and how these processes fail under adverse conditions known to produce brain damage.

\section{REFERENCES}

1. Sokoloff L, Reivich M, Kennedy C, Des Rosiers MH, Patak CS, Pettigrew KD, Sakurada O, Rhinohara M 1977 The $\left[{ }^{14} \mathrm{C}\right]$ deoxyglucose method for the measurement of local cerebral glucose utilization: Theory, procedure, and normal values in the conscious and anesthetized albino rat. I Neurochem 28:897-916

2. Sokoloff L 1981 Localization of functional activity in the central nervous system by measurement of glucose utilization with radioactive deoxyglucose. J Cereb Blood Flow Metabol 1:7-36

3. Chugani HT, Phelps ME 1986 Maturational changes in cerebral function in infants determined by ${ }^{18} \mathrm{FDG}$ positron emission tomography. Science 231:840-843

4. Chugani HT, Phelps ME, Mazziotta JC 1987 Positron emission tomography study of human brain functional development. Ann Neurol 22:487-497

5. Kennedy C 1981 Energy metabolism of the brain. In: Sinclair JC, Warshaw JB, Bloom RS (eds), Perinatal Brain Insult. Mead Johnson and Co., Evansville, IN, pp 30-42

6. Duffy TE, Cavazzuti M, Cruz NF, Sokoloff L 1982 Local cerebral glucose metabolism in newborn dogs: effect of hypoxia and halothane anesthesia. Ann Neurol 11:233-246

7. Abrams RM, Ito M, Frisinger JE, Patlak CS, Pettigrew KD, Kennedy C 1984 Local cerebral glucose utilization in fetal and neonatal sheep. Am J Physiol 246:R608-R618

8. Lyons DT, Vasta F, Vannucci RC 1987 Autoradiographic determination of regional cerebral blood flow in the immature rat. Pediatr Res 21:471-476

9. Vannucci RC, Duffy TE 1974 Influence of birth on carbohydrate and energy metabolism in rat brain. Am J Physiol 226:933-940

10. Fuglsang A, Lomholt M, Gjedde A 1986 Blood-brain transfer of glucose and glucose analogs in newborn rats. J Neurochem 46:1417-1428

11. Duffy TE, Kohle SJ, Vannucci RC 1975 Carbohydrate and energy metabolism in perinatal rat brain: relation to survival in anoxia. J Neurochem $24: 271-$ 276

12. Welsh FA, Vannucci RC, Brierley JB 1982 Columnar alterations of NADH fluorescence during hypoxia-ischemia in immature rat brain. J Cereb Blood Flow Metabol 2:221-228

13. Nelson T, Lucignani G, Atlas S, Crane AM, Dienel GA, Sokoloff L 1986 Reexamination of glucose-6-phosphatase activity in the brain in vivo: no evidence for a futile cycle. Science 229:60-62

14. Hawkins RA, Miller AL 1978 Loss of radioactive 2-deoxy-d-glucose-6-phosphate from brains of consciouis rats: implications for quantitative autoradiographic determination of regional glucose utilization. Neuroscience $3: 251$ 258

15. Huang M-T, Veech RL 1986 Metabolic fluxes between $\left[{ }^{14} \mathrm{C}\right] 2$-deoxy-d-glucose and $\left[{ }^{14} \mathrm{C}\right] 2$-deoxy-d-glucose-6-phosphate in brain in vivo. $\mathrm{J}$ Neurochem 44:567-573

16. Gjedde A 1987 Does deoxyglucose uptake in the brain reflect energy metabo- 
lism? Biochem Pharmacol 36:1853-1861

17. McIlwain H, Bachelard HS 1971 Biochemistry and the Central Nervous System. Churchill Livingstone, London, pp 406-444

18. Wilson JE 1972 The relationship between glycolytic and mitochondrial enzymes in the developing rat brain. J Neurochem 19:223-227

19. Pardridge WM, Crane PD, Mietus LJ, Oldendorf WH 1982 Nomogram for 2deoxyglucose lumped constant for rat brain cortex. J Cereb Blood Flow Metabol 2:197-202

20. Tanaka K, Welsh FA, Greenberg JH, O'Flynn R, Harris VA, Reivich M 1985 Regional alterations in glucose consumption and metabolite levels during postischemic recovery in cat brain. J Cereb Blood Flow Metabol 5:502-511

21. Rice JE, Vannucci RC, Brierley JB 1981 The influence of immaturity on hypoxic-ischemic brain damage in the rat. Ann Neurol 9:131-141

22. Milstein JM, White JG, Swaiman KF 1968 Oxidative phosphorylation in mitochondria of developing rat brain. J Neurochem 15:411-415

23. Holtzman D, Moore CL 1973 Oxidative phosphorylation in immature rat mitochondria. Biol Neonate 22:230-242

24. Jones MD, Burd LI, Makowski EI, Meschia G, Battaglia FC 1975 Cerebral metabolism in sheep: a comparative study of the adult, the lamb and the fetus. Am J Physiol 229:235-239

25. Levitsky LL, Fisher DE, Paton JB, Delannoy CW 1977 Fasting plasma levels of glucose, acetoacetate, $D$ - $\beta$-hydroxybutyrate, glycerol and lactate in the baboon infant: Correlation with cerebral uptake of substrates and oxygen. Pediatr Res 11:298-302

26. Hernandez MJ, Vannucci RC, Salcedo A, Brennan RW 1980 Cerebral blood flow and metabolism during hypoglycemia in newborn dogs. J Neurochem 35:622-628

27. Hawkins RA, Williamson DH, Krebs HA 1971 Ketone-body utilization by adult and suckling rat brain in vivo. Biochem J 122:13-18

28. Moore TJ, Lione AP, Sugden MC, Regen DM $1976 \beta$-Hydroxybutyrate transport in rat brain: developmental and dietary modulations. Am J Physiol 230:619-630

29. Miller AL, Kiney CA, Corddry DH, Staton DM 1982 Interactions between glucose and ketone body use by developing brain. Dev Brain Res 4:433-450

30. Nehlig A, Pereira de Vasconcelos A, Boyet S 1988 Quantitative autoradiographic measurement of local cerebral glucose utilization in freely moving rats during postnatal development. J Neurosci 8:2321-2333

31. Mujsce DJ, Christensen MA, Vannucci RC 1989 Regional cerebral blood flow and glucose utilization during hypoglycemia in newborn dogs. Am J Physiol (in press)

32. Stein DT, Vannucci RC 1988 Calcium accumulation during the evolution of hypoxic-ischemic brain damage in the immature rat. J Cereb Blood Flow Metabol 8:834-842

33. Vannucci RC, Lyons DT, Vasta F 1988 Regional cerebral blood flow during hypoxia-ischemia in immature rats. Stroke 19:245-250

34. Cremer JE, Cunningham VJ, Pardridge WM, Braun LD, Oldendorf WH 1979 Kinetics of blood-brain barrier transport of pyruvate, lactate and glucose in suckling, weanling and adult rats. $\mathbf{J}$ Neurochem 33:439-445

35. Vannucci RC, Duffy TE 1976 Carbohydrate metabolism in fetal and neonatal rat brain during anoxia and recovery. Am J Physiol 230:1269-1275 